BMJ Open Diabetes Research \& Care

\title{
Exercise modes and their association with hypoglycemia episodes in adults with type 1 diabetes mellitus: a systematic review
}

\author{
Saima Hasan, ${ }^{1}$ Sian M Shaw, ${ }^{1}$ Leslie H Gelling, ${ }^{1}$ Catherine J Kerr, ${ }^{2}$ \\ Catherine A Meads ${ }^{1}$
}

To cite: Hasan S, Shaw SM, Gelling LH, et al. Exercise modes and their association with hypoglycemia episodes in adults with type 1 diabetes mellitus: a systematic review. BMJ Open Diab Res Care Published Online First: [please include Day Month Year]. doi:10.1136/ bmjdrc-2018-000578

$\checkmark$ Additional material is published online only. To view please visit the journal online (http://dx.doi.org/10.1136/ bmjdrc-2018-000578).

Received 10 July 2018 Revised 7 August 2018 Accepted 16 August 2018
Check for updates

\section{(C) Author(s) (or their} employer(s)) 2018. Re-use permitted under CC BY-NC. No commercial re-use. See rights and permissions. Published by BMJ.

${ }^{1}$ Faculty of Health, Social Care and Education (FHSCE), Anglia Ruskin University, Cambridge, UK

${ }^{2}$ Freelance Research Consultant, Cambridge, UK

Correspondence to Professor Catherine A Meads; catherine.meads@anglia.ac.uk

\section{ABSTRACT}

Objective Type 1 diabetes mellitus rates are rising worldwide. The health benefits of physical exercise in this condition are many, but more than $60 \%$ do not participate, mainly from fear of hypoglycemia. This systematic review explores the effects of physical exercise modes on blood glucose levels in adults for hypoglycemia prevention.

Research design and methods Predefined inclusion criteria were randomized or non-randomized cross-over trials of healthy non-obese adults with type 1 diabetes mellitus. Exercise interventions used standardized protocols of intensity and timing. Outcomes included hypoglycemia during or after exercise, and acute glycemic control. Medline, Cumulative Index to Nursing and Allied Health Literature, Allied and Complementary Medicine Database, SPORTDiscus, CochraneCENTRAL (1990 to 11 January 2018), and Embase (1988 to 9 April 2018) were searched using keywords and Medical Subject Heading (MeSH) terms. Inclusions, data extraction and quality assessment using the Critical Appraisal Skills Programme checklists were done by one researcher and checked by a second. Review Manager (V.5.3) was used for metaanalysis where four or more outcomes were reported. Results From 5459 citations, we included 15 small crossover studies (3 non-randomized), 13 assessing aerobic (intermittent high-intensity exercise (IHE) vs continuous, or continuous vs rest) and 2 assessing resistance exercise versus rest. Study quality was good, and all outcome measures were reported. Thirteen gave hypoglycemia results, of which five had no episodes. Meta-analysis of hypoglycemia during or after IHE compared with continuous exercise showed no significant differences $\left(n=5,0 R=0.68(95 \%\right.$ Cl 0.16 to 2.86$\left.), l^{2}=56 \%\right)$. For blood glucose there was little difference between groups at any time point.

Conclusion IHE may be safer than continuous exercise because of lesser decline in blood glucose, but more research needs to demonstrate if this would be reflected in hypoglycemic episode rates.

Trial registration number CRD42018068358.

\section{INTRODUCTION}

The prevalence of diabetes mellitus has been increasing worldwide, with the number rising

\section{Significance of this study}

What is already known about this subject?

- Numerous studies have tried to find safe and effective strategies to maintain normal blood glucose level in people with type 1 diabetes mellitus (T1DM) during and following exercise.

- It is currently unclear which types of exercise are best in order to avoid hypoglycemia during and/or after exercise.

What are the new findings?

- This systematic review presents all available evidence about different exercise strategies and their effects on blood glucose and hypoglycemic events in people with T1DM to determine the best strategy to minimize the risk of these adverse outcomes.

How might these results change the focus of research or clinical practice?

- Intermittent high-intensity exercise may be safer than continuous exercise because of lesser decline in blood glucose, but more research needs to demonstrate if this would be reflected in the number of hypoglycemic episodes.

- More research is needed comparing aerobic and resistance exercise.

from 108 million to 422 million between 1980 and $2014^{1}$ and estimated to be around 552 million by $2030 .^{2}$ About $5 \%-10 \%$ has type 1 diabetes mellitus, an autoimmune disease with absolute deficiency of insulin due to beta-cell destruction, ${ }^{3}$ and the incidence of this type of diabetes mellitus is also increasing. ${ }^{4}$

Although insulin forms the conventional treatment for type 1 diabetes mellitus, a triad of insulin, balanced diet and better fitness level through regular physical activity is essential in maintaining a good blood glucose (BG) level and complication-free life. ${ }^{5}$

The health benefits of physical activity in type 1 diabetes mellitus are many, including 
improvements in insulin sensitivity of the whole body, reduced risk of cardiovascular diseases, hypertension, and malignancy, and increased overall life expectancy, along with increased self-esteem and sense of well-being. ${ }^{6}$ It is also observed that the frequency and severity of diabetic complications such as nephropathy, retinopathy, neuropathy and cardiovascular diseases are much less in individuals with type 1 diabetes mellitus who engage in more frequent and vigorous physical activity, depending on their fitness levels, compared with those leading a relatively sedentary life with little or no physical activity. ${ }^{7}$ It is recommended for individuals with type 1 diabetes mellitus to engage in a strategic and integrated exercise regimen. ${ }^{8}$ Many people with type 1 diabetes mellitus are also interested in participating in sports and are often motivated by famous athletes with diabetes mellitus such as Sir Steve Redgrave. ${ }^{9}$

More than $60 \%$ of people with type 1 diabetes mellitus do not participate in physical activity. ${ }^{10}$ The contributing factors toward this include lack of time, motivation, support from family and friends, and lack of knowledge regarding appropriate physical activity such as physical exercise, ${ }^{10}$ but the principal factor seems to be fear of hypoglycemia. ${ }^{11}$

Numerous studies have tried to find safe and effective strategies to maintain normal BG level during and following exercise. ${ }^{12-16}$ Carbohydrate supplements and insulin adjustments are effective ways to prevent hypoglycemia, although these are often difficult to regulate, come with potential side effects and used on a trial-anderror basis. Changes in BG level are different with each exercise type and intensity. ${ }^{17}$ It is currently unclear how best to avoid hypoglycemia during different modes of physical exercise in people with type 1 diabetes mellitus.

This systematic review explores the effects of different types and intensities of physical exercise on BG levels in adults with type 1 diabetes mellitus, during and up to 24 hours following exercise, to understand the most effective exercise-related strategy for hypoglycemia prevention.

\section{RESEARCH DESIGN AND METHODS}

This study was registered with PROSPERO, trial registration number CRD42018068358. The predefined inclusion criteria were randomized or non-randomized cross-over trials or randomized controlled trials of healthy, physically active, non-obese adults (male and female) aged 18-50 years diagnosed with type 1 diabetes mellitus and taking insulin. We included both trained athletes and untrained participants to widen the generalizability of the systematic review. Obesity was excluded because of the possibility that participants might have signs of type 2 diabetes mellitus as well as type 1 diabetes mellitus. ${ }^{18}$ Participants had to be taking part in shortterm exercise interventions consisting of a standardized exercise protocol with controlled intensity and timing. The type of exercise was classified into aerobic, intermittent high-intensity and resistance exercises. Aerobic exercise was defined as continuous exercise involving a large group of muscles in a repetitive manner, for example cycling, running and walking. ${ }^{19}$ Intermittent high-intensity exercise (IHE) entailed short repeated bouts of intense activity (such as sprints), interspersed with periods of moderate-intensity exercise or rest. ${ }^{16}$ Such exercise interventions simulate sports activities such as soccer, hockey and rugby, which involve continuous exercise as well as sprints. Resistance exercise incorporates anaerobic activities of short and intense nature (such as strength training and weightlifting). Comparators could be either rest or another type of short-term exercise. The primary outcome was hypoglycemia during, immediately after exercise sessions, or in the early or late recovery period (such as nocturnal hypoglycemia). Hypoglycemia can be defined as BG level below $4 \mathrm{mmol} / \mathrm{L}^{20}$ Other outcomes included acute glycemic control and requirement of carbohydrate consumption.

Excluded were participants with markers of acute complications (ketonuria, microalbuminuria) to ensure participants had no conditions such as diabetic ketoacidosis, or with pre-existing chronic complications such as diabetic retinopathy, nephropathy or neuropathy because exercise can result in deterioration of these conditions. ${ }^{6}$ Also excluded were studies on animals, children or adolescents aged less than 18 years, people with type 2 diabetes mellitus or studies with a mix of both conditions. Excluded interventions were those involving prolonged exercise sessions, observing effects on chronic glycemic control as measured by glycosylated hemoglobin $\left(\mathrm{HbA}_{1 \mathrm{C}}\right)$, exercise in free living conditions, where insulin was given during the exercise itself, or where $\mathrm{BG}$ levels were artificially manipulated.

We searched the following databases (platforms, dates): Medline (EBSCO, 1 January 1990-11 January 2018), Embase (Ovid, 1 January 1988-9 April 2018), Cumulative Index to Nursing and Allied Health Literature (EBSCO, 1 January 1990-11 January 2018), Allied and Complementary Medicine Database (EBSCO, 1 January 1990-11 January 2018), SPORTDiscus (EBSCO, 1 January 1990-11 January 2018) and CENTRAL (Cochrane Library, 1 January 1990-11 January 2018). We did keyword and $\mathrm{MeSH}$ searches for terms and synonyms for diabetes, exercise, hypoglycemia and BG, with no language restrictions. Search terms used are shown in .online supplementary appendix. We checked the reference lists of relevant reviews and meta-analyses for additional studies. We transferred all relevant titles and abstracts to EndNote (V.X8) for assessment.

\section{Data extraction and quality assessment}

Two investigators ( $\mathrm{SH}$ and $\mathrm{CAM}$ ) checked the study eligibility. One independently extracted data from studies (SH) using a standardized, predesigned extraction form in Microsoft Excel 2007, and everything was checked by a second investigator (CAM). Disagreements were resolved through discussion. We assessed the quality of included studies with the criteria for randomized controlled trials 
set by the Critical Appraisal Skills Programme, ${ }^{21}$ focusing on randomization, allocation concealment, presence of masking, explanation of withdrawals, presence or absence of intention-to-treat analysis, and external validity. As the majority of the included studies had a cross-over design, risk of bias was analyzed by indicators in the Cochrane Handbook $^{22}$ : (1) suitability of cross-over design; (2) randomness in the allocation of treatments; (3) presence of carry-over effects as determined by washout periods; and (4) use of appropriate paired statistical analysis.

\section{Statistical analysis}

We tabulated the characteristics and results of all included studies; analysis was mainly narrative. We used Review Manager (V.5.3, Cochrane Library) for exploratory meta-analyses where four or more similar outcomes for the same type of exercise and comparator were reported. We used random-effects models because of heterogeneity of participants and interventions. The only outcome meta-analyzed was of categorical measures and we used ORs. Risk of publication bias was not assessed by funnel plot due to lack of studies reporting similar outcomes. There were insufficient studies to warrant exploration of heterogeneity of effectiveness using meta-regression.

\section{RESULTS}

We identified 5459 titles and abstracts, from which we assessed 56 full-text articles for inclusion, and 15 studies were included in the systematic review (see table 1), all in English. Excluded studies after retrieving full text are shown in online supplementary table W1. The characteristics of the included studies are shown in table 1 and participant characteristics are in table 2. All included studies had cross-over designs, three were non-randomized, eleven were randomized and one was part-randomized (see online supplementary table W2). The number of included participants ranged from 7 to 13, with ages ranging from 18 to 50 years, and all participants were devoid of any complications and in good metabolic control, with a healthy body mass index. Across the studies, $80 \%$ of the participants were male. Four studies included only men, ${ }^{23-26}$ while the remaining studies included both men and women, with the percentage of women ranging from $7.7 \%$ to $56 \%$. All studies recruited participants diagnosed with type 1 diabetes mellitus for at least 1 year who were on regular insulin therapy. Two studies included trained athletes, ${ }^{27} 28$ one included two trained and ten recreationally active participants, ${ }^{29}$ and the other studies included participants who were regularly active.

The interventions consisted of short-term exercise sessions with controlled time and intensity. Six studies ${ }^{24} 26$ 30-33 involved short-term continuous aerobic exercise sessions with resting control as comparator. Two studies ${ }^{30} 33$ involved walking on a treadmill, and the rest used cycle ergometers for the exercise intervention. The duration of exercise ranged from 30 to $60 \mathrm{~min}$. Exercise intensity was determined by heart rate reserve in two studies ${ }^{24} 30$ and the remaining studies used maximal oxygen uptake $\left(\mathrm{VO}_{2 \max }\right)$ to determine exercise intensity. All the exercise sessions were of moderate intensity, with one study having low $\left(25 \% \mathrm{VO}_{2 \max }\right)$, moderate $\left(50 \% \mathrm{VO}_{2 \max }\right)$ and high $(75 \%$ $\left.\mathrm{VO}_{2 \max }\right)$ intensities of exercise. Exercise sessions were performed in the morning except in three studies: Maran et $a l^{25}$ conducted them at approximately 14:00, while Iscoe and Riddell ${ }^{27}$ and Yardley et $a t^{29}$ conducted experiments at 17:00. Moser et $a t^{28}$ did not report on experiment timing.

Seven studies 23252728 34-36 observed the effect of IHE (combined high-intensity exercise interspersed with moderate-intensity exercise or rest). The duration of exercise ranged from 30 to $90 \mathrm{~min}$. All studies determined IHE protocol by maximal sprints interspersed by moderate continuous exercise on a cycle ergometer, except the study by Moser $e t a t^{28}$ which used three different workloads to determine intensities, using lactate turn-point thresholds. Campbell et $a l^{34}$ also incorporated a different methodological approach for the exercise sessions, where the intervention protocol involved continuous treadmill running and intermittent exercise involved an intermittent running session based on the Loughborough Intermittent Shuttle Test, which was designed to simulate games-type activity.

Two studies observed the effect of resistance exercise on acute glycemic control. ${ }^{29}{ }^{37}$ In the study by Yardley et $a l^{29}$ both continuous and resistance exercises were performed against a resting control. The intensity of continuous exercise was quantified by $\mathrm{VO}_{2 \max }$ and resistance exercise involved sets of weightlifting within certain time limits. Turner $e t a \hat{l}^{37}$ quantified exercise intensity at $67 \% \pm 3 \%$ of one repetition maximum (i.e. repetition of exercise at maximum intensity) with different amounts per session (one set=14 $\mathrm{min}$, two sets $=28 \mathrm{~min}$ and three sets=42 $\mathrm{min}$ ). Hence, heterogeneity regarding study interventions can also be observed in the resistance exercise protocols.

Overall quality of the included studies was generally good, with clear and well-represented results, and with all participants being accounted for in each trial. Among the randomized trials, none mentioned the method of randomization, and only Bally et $a l^{23}$ mentioned the method of allocation concealment (sealed opaque envelopes). In Yardley et $a l$ 's study, ${ }^{29}$ all control sessions happened first, then participants were randomly assigned to the two types of exercise, hence part-randomization. Three studies ${ }^{28} 3033$ used non-randomized cross-over designs with fixed order of trial arms, which may have introduced a period effect. Three studies ${ }^{27} 2932$ described participant blinding, and in another three trials lack of blinding was specifically stated, ${ }^{23} 3137$ while the remaining trials provided no information regarding blinding. Risk of bias in cross-over studies was minimized by washout periods to avoid carry-over effects between trial arms (see online supplementary table W3 for details). Trial arms for most studies were separated by at least 1 week, although for Soo $e t a \hat{l}^{2}$ the duration was 2 days. 
Table 1 Study characteristics

\begin{tabular}{|c|c|c|c|c|}
\hline Study & Study design & $\begin{array}{l}\text { Exercise intervention type, duration } \\
\text { (min), description, intensity }\end{array}$ & Comparator & $\begin{array}{l}\text { Timing of blood glucose } \\
\text { measurements }\end{array}$ \\
\hline Bally et $\left.a\right|^{23}$ & $\begin{array}{l}\text { Randomized } \\
\text { cross-over trial }\end{array}$ & $\begin{array}{l}\text { Cycling at } 50 \% \mathrm{VO}_{2 \max } \text { for } 90 \text { min } \\
\text { with IHE with } 9 \times 10 \mathrm{~s} \text { maximal sprints } \\
\text { every } 10 \text { min at } 120 \% \text { of individual } \\
\text { peak workload followed by } 50 \mathrm{~s} \\
\text { recovery phase. }\end{array}$ & $\begin{array}{l}\text { Cycling at } 50 \% \\
\mathrm{VO}_{2 \max } \text { for } 90 \mathrm{~min} \text {. }\end{array}$ & $\begin{array}{l}\text { During } 90 \text { min of exercise, } \\
120 \text { min postexercise and } \\
\text { postexercise overnight } \\
\text { follow-up. }\end{array}$ \\
\hline $\begin{array}{l}\text { Hinojosa and } \\
\text { Heiss }^{30}\end{array}$ & Cross-over trial & $\begin{array}{l}\text { Walking at } 50 \%-60 \% \text { maximum heart } \\
\text { rate for } 15 \mathrm{~min} \text {. }\end{array}$ & Sitting quietly. & $\begin{array}{l}\text { During and up to } 120 \mathrm{~min} \\
\text { following exercise. }\end{array}$ \\
\hline $\begin{array}{l}\text { Iscoe and } \\
\text { Riddell }^{27}\end{array}$ & $\begin{array}{l}\text { Randomized } \\
\text { cross-over trial }\end{array}$ & $\begin{array}{l}\text { Cycling at } 50 \% \mathrm{VO}_{2 \max } \text { with } 9 \times 15 \mathrm{~s} \\
\text { maximal sprints every } 5 \text { min. }\end{array}$ & $\begin{array}{l}\text { Cycling at } 55 \% \\
\mathrm{VO}_{2 \max }\end{array}$ & $\begin{array}{l}\text { During and up to } 24 \text { hours } \\
\text { following exercise. }\end{array}$ \\
\hline Jankovec et $a l^{24}$ & $\begin{array}{l}\text { Randomized } \\
\text { cross-over trial }\end{array}$ & $\begin{array}{l}\text { Cycling at } 60 \% \text { hour reserve for } 2 \times 30 \\
\text { min. }\end{array}$ & Resting. & During exercise. \\
\hline Maran et $a l^{25}$ & $\begin{array}{l}\text { Randomized } \\
\text { cross-over trial }\end{array}$ & $\begin{array}{l}\text { Cycling at } 40 \% \mathrm{VO}_{2 \max } \text { with } 15 \times 5 \mathrm{~s} \\
\text { maximal sprints at } 85 \% \text {. }\end{array}$ & $\begin{array}{l}\text { Cycling at } 40 \% \\
\mathrm{VO}_{2 \max }\end{array}$ & $\begin{array}{l}\text { During and up to } 24 \text { hours } \\
\text { following exercise. }\end{array}$ \\
\hline Moser et $\left.a\right|^{28}$ & Cross-over trial & $\begin{array}{l}\text { Cycling at control } A, B \text { or } C \text { followed } \\
\text { by } 120 \mathrm{~s}, 60 \mathrm{~s} \text { or } 20 \mathrm{~s} \text { recovery } \\
\text { period, followed by high-intensity } \\
\left.\text { peak workload ( } P_{\text {Peak }}\right) \text { for } 20 \mathrm{~s} \\
\text { (followed by } 3 \mathrm{~s} \text { active recovery at } \\
40 \mathrm{~W} \text { and } 3 \mathrm{~s} \text { passive recovery at } \mathrm{OW} \text { ). }\end{array}$ & $\begin{array}{l}\text { Cycling at } 3 \text { target } \\
\text { workloads: } \\
\text { A: } 5 \% P_{\text {max }} \text { from IET } \\
\text { below } P_{\text {LTP1 }} \text {. } \\
\text { B: } 5 \% P_{\text {max }} \text { from IET } \\
\text { above } P_{\text {LTP1 }} \\
\text { C: } 5 \% P_{\text {max }} \text { from IET } \\
\text { below } P_{\text {LTP2 }}\end{array}$ & $\begin{array}{l}\text { During and } 24 \text { hours } \\
\text { postexercise. }\end{array}$ \\
\hline Peter et $a l^{31}$ & $\begin{array}{l}\text { Randomized } \\
\text { cross-over trial }\end{array}$ & Cycling at $65 \%$ (SD 10.1\%) $\mathrm{VO}_{2 \text { peak }}$ & Resting. & $\begin{array}{l}\text { During and } \\
2 \text { hours postexercise. }\end{array}$ \\
\hline $\begin{array}{l}\text { Rabasa-Lhoret } \\
\text { et }\left.a\right|^{26}\end{array}$ & $\begin{array}{l}\text { Randomized } \\
\text { cross-over trial }\end{array}$ & $\begin{array}{l}\text { Cycling at } 25 \%, 50 \% \text {, or } 75 \% \mathrm{VO}_{2 \max } \\
\text { for } 30 \text { or } 60 \mathrm{~min} .\end{array}$ & Resting. & $\begin{array}{l}\text { During exercise ( } 30 \text { and } 90 \\
\text { min), } 18 \text { hours postexercise } \\
\text { and at rest. }\end{array}$ \\
\hline Soo et $\left.a\right|^{32}$ & $\begin{array}{l}\text { Randomized } \\
\text { partial cross- } \\
\text { over trial }\end{array}$ & $\begin{array}{l}\text { Cycling at } 60 \% \mathrm{VO}_{2 \max }(50 \% \text { hour } \\
\text { reserve) for } 45 \mathrm{~min} \text {. }\end{array}$ & Resting. & $\begin{array}{l}\text { During and } 60 \text { min following } \\
\text { exercise. }\end{array}$ \\
\hline Turner et $\left.a\right|^{37}$ & $\begin{array}{l}\text { Randomized } \\
\text { cross-over trial }\end{array}$ & $\begin{array}{l}\text { Lifting weights for } 14 \text { min ( } 1 \text { set of } 8 \\
\text { exercises), } 28 \text { min ( } 2 \text { sets) or } 42 \text { min } \\
\text { (3 sets). }\end{array}$ & Resting for 14 min. & $\begin{array}{l}\text { At rest and up to } 60 \text { min of } \\
\text { recovery postexercise. }\end{array}$ \\
\hline $\begin{array}{l}\text { Yamanouchi et } \\
\mathrm{al}^{33}\end{array}$ & Cross-over trial & Walking at $<50 \% \mathrm{VO}_{2 \max }$ for $30 \mathrm{~min}$. & Resting. & $\begin{array}{l}\text { During and } 2 \text { hours, } \\
\text { postexercise. }\end{array}$ \\
\hline Yardley et $a l^{29}$ & $\begin{array}{l}\text { Part-randomized } \\
\text { cross-over trial }\end{array}$ & $\begin{array}{l}\text { 1. Weightlifting: } 3 \text { sets ( } 7 \text { exercises } \\
\times 8 \text { repetitions). } \\
\text { 2. Walking/running at } 60 \% \mathrm{VO}_{2 \max } \text { for } \\
45 \text { min. }\end{array}$ & Resting. & $\begin{array}{l}\text { During exercise, } 6 \text { hours } \\
\text { postexercise and } 24 \text { hours } \\
\text { postexercise. }\end{array}$ \\
\hline
\end{tabular}

${ }^{*}$ Third exercise condition excluded as not comparable.

$B G$, blood glucose; IET, incremental exercise test; IHE, intermittent high-intensity exercise; $P_{L T P 1}$, power output at the first lactate turn point; $\mathrm{P}_{\text {LTP2 }}$, power output at the second lactate turn point; $\mathrm{P}_{\max }$, maximal power output; $\mathrm{VO}_{2 \max }$, maximal oxygen uptake; $\mathrm{VO}_{2 \text { peak }}$, peak oxygen uptake; W, watt. 
Table 2 Participant characteristics

\begin{tabular}{|c|c|c|c|c|c|c|}
\hline Study & $\begin{array}{l}\text { Participants } \\
\text { N (gender) }\end{array}$ & $\begin{array}{l}\text { Age (years) } \\
\text { Mean (SD) }\end{array}$ & $\begin{array}{l}\text { BMI } \\
\text { Mean (SD) }\end{array}$ & $\begin{array}{l}\text { Duration } \\
\text { of diabetes } \\
\text { (years) } \\
\text { Mean (SD) }\end{array}$ & $\begin{array}{l}\mathrm{HbA}_{1 \mathrm{c}} \\
\text { Mean (SD) }\end{array}$ & $\begin{array}{l}\text { Baseline } \mathrm{VO}_{2 \max } \\
\text { (mL/kg/min) } \\
\text { Mean (SD) }\end{array}$ \\
\hline Bally et $a l^{23}$ & 12 (all M) & $26.2(3.9)$ & $25.2(3.4)$ & $14.2(6.2)$ & $7(0.6)$ & $47.9(10.2)$ \\
\hline Campbell et $a l^{34}$ & $9(7 \mathrm{M} / 2 \mathrm{~F})$ & $35(4.0)$ & $26.8(1.1)$ & $25(4)$ & $8.1(0.2)$ & $41.8(1.6)$ \\
\hline Dubé et $a l^{35}$ & $11(5 \mathrm{M} / 6 \mathrm{~F})$ & $26.5(6.6)$ & $25.8(2.7)$ & $12.2(5.1)$ & $7.3(0.4)$ & $33.4(6.5)$ \\
\hline Guelfi et $a l^{16}$ & $7(4 \mathrm{M} / 3 \mathrm{~F})$ & $21.6(4.0)$ & $24.7(3.7)$ & $8.6(5.0)$ & $7.4(1.5)$ & $39.3(7.4)$ \\
\hline Hinojosa and Heiss ${ }^{30}$ & $7(4 \mathrm{M} / 3 \mathrm{~F})$ & $22.3(4.3)$ & $25.4(3.5)$ & $12.7(3.5)$ & $7.4(0.5)$ & NR \\
\hline Iscoe and Riddel| ${ }^{27}$ & $11(5 \mathrm{M} / 6 \mathrm{~F})$ & $35.1(3.5)$ & NR & $15.6(5.6)$ & $7.8(0.4)$ & $42.4(1.6)$ \\
\hline Jankovec et al $\left.\right|^{24}$ & 12 (all M) & $33.4(8.47)$ & $25.8(3.67)$ & $16.4(8.57)$ & $8.4(0.95)$ & NR \\
\hline Maran et $a l^{25}$ & 8 (all M) & $34(7)$ & $24(2)$ & $14.3(8)$ & $7.14(0.6)$ & $33.7(6.5)$ \\
\hline Moser et $\left.a\right|^{28}$ & 7 (all M) & $24(5.3)$ & $23.9(2.5)$ & $>1$ years & $7.4(0.6)$ & $52(8.2)$ \\
\hline Peter et $\left.a\right|^{31}$ & $13(12 \mathrm{M} / 1 \mathrm{~F})$ & $33.3(6.5)$ & 26.8 (3.3) & $\geq 1$ years & $7.6(1.3)$ & NR \\
\hline Rabasa-Lhoret et al ${ }^{26}$ & 8 (all M) & $33(8.8)$ & $23.4(1.7)$ & $12.6(8.8)$ & $6.1(0.006)$ & $37.8(3.5)$ \\
\hline Soo et $a l^{32}$ & $9(8 M / 1 F)$ & $25.8(7.0)$ & $22.8(1.2)$ & $7.3(5.7)$ & NR & NR \\
\hline Turner et $a l^{37}$ & $8(7 \mathrm{M} / 1 \mathrm{~F})$ & $38(6)$ & $26.9(1.5)$ & $15(4.5)$ & $8.7(1.0)$ & NR \\
\hline Yamanouchi et al ${ }^{33}$ & $6(3 M / 3 F)$ & $42.7(13.6)$ & $20.3(2.3)$ & $5.6(6.4)$ & $7.4(0.9)$ & NR \\
\hline Yardley et $a l^{29}$ & $12(10 \mathrm{M} / 2 \mathrm{~F})$ & 31.8 (15.3) & $25.3(3)$ & $12.5(10)$ & $7.1(1.1)$ & $51.2(10.8)$ \\
\hline
\end{tabular}

BMI, body mass index; F, female; $\mathrm{HbA}_{1 \mathrm{C}}$, glycosylated hemoglobin; $\mathrm{M}$, male; $\mathrm{NR}$, not recorded; $\mathrm{VO}_{2 \max }$, maximal oxygen uptake.

Apart from the studies by Iscoe and Riddell ${ }^{27}$ and Moser et $a l^{28}$ where they recruited only trained athletes for the trial, the other studies recruited non-trained physically active subjects, so results are likely to be applicable to a wide spectrum of fitness levels in the general population. Ten studies required participants to avoid exercise in the 12-48 hours pretrial (see online supplementary table W3), and in Soo $e t a l^{32}$ they were advised to maintain their usual lifestyle. Four studies did not provide any information regarding preintervention physical activity, 242633 and four studies gave no information about preintervention diet t4 293033 (see online supplementary table W4). Seven studies checked for hypoglycemia in the 24-48 hours preceding the trial, and it was postponed in participants in the event of preceding hypoglycemia. ${ }^{23-25} 28$ 35-37 Online supplementary table W4 shows the use of carbohydrate to counterbalance hypoglycemia during exercise.

Participants were treated similarly and equally at the start of the trial for each study. Studies described how accurate measurement of outcomes was performed, and all outcome measures were reported in some way. Thirteen studies reported on whether participants had hypoglycemic events or not, the number of participants with hypoglycemic events, and the number of episodes or mean events per participant, while two studies ${ }^{33} 37$ did not report this outcome at all (see table 3). Not all studies measured late-onset postexercise hypoglycemia (LOPEH), so intervention effects on nocturnal hypoglycemia were not always reported (see table 3 ).

For hypoglycemic events during or just after IHE compared with continuous exercise, meta-analysis showed no significant difference between groups $(n=5$,
$\mathrm{OR}=0.68$ (95\% CI 0.16 to 2.86$), \mathrm{I}^{2}=56 \%$; see figure 1$)$. However, it is noticeable in the meta-analysis that four studies favored intermittent exercise and one favored continuous exercise, ${ }^{25}$ but it is unclear as to why this study showed opposite results.

For all studies, the glycemic profiles for the study population were expressed as means; individual patient data were not available so individually paired statistical analyses were not possible. Seven studies ${ }^{240-33} 3536$ measured acute changes in BG during and immediately after exercise, with the recovery period ranging from 60 to 120 min, but not for longer (see online supplementary tables W5 and W6). However no BG changes during resistance exercise were reported by Turner $e t a \vec{l}^{37}$; only data at rest and in the early and late postexercise recovery periods were available. Also, none of the studies comparing continuous exercise with rest measured nocturnal BG. The results show that, for IHE compared with continuous exercise, there was little difference between groups at any time point. In continuous exercise compared with rest studies, unsurprisingly, exercise resulted in lower BG levels during and after exercise.

\section{DISCUSSION}

\section{Summary of results}

Searches identified 15 included studies, of which 7 evaluated IHE compared with continuous exercise, and 6 evaluated continuous exercise compared with rest. Two studies evaluated resistance exercise. All were of cross-over design and had few participants. Hypoglycemic episodes were not reported in three studies, none occurred in either arm in 
Table 3 Results: hypoglycemia incidents in intervention compared with con

IHE compared with continuous exercise

\section{Evening or}

nocturnal hypos

(n) (or mean (SD))

\section{Evening or}

Hypos (n) during/ nocturnal hypos

\begin{tabular}{|c|c|c|c|c|c|}
\hline Study & $\begin{array}{l}\text { Hypos (n) during/ } \\
\text { after IHE }\end{array}$ & $\begin{array}{l}\text { after continuous } \\
\text { exercise }\end{array}$ & $\begin{array}{l}\text { (n) (or mean (SD)) } \\
\text { IHE group }\end{array}$ & $\begin{array}{l}\text { Continuous } \\
\text { exercise }\end{array}$ & $\begin{array}{l}\text { Definition of } \\
\text { hypoglycemia }\end{array}$ \\
\hline Bally et $a l^{23}$ & None* & None* & 1.18 (0.42)† & $\begin{array}{l}0.58(0.32) \dagger \\
(p=0.39)\end{array}$ & $\mathrm{BG}<4 \mathrm{mmol} / \mathrm{L}$ \\
\hline Campbell et $a l^{34}$ & $\begin{array}{l}1 \text { hour } \\
\text { postexercise: } 2 / 9 \\
(22 \%)\end{array}$ & $\begin{array}{l}1 \text { hour } \\
\text { postexercise: } 3 / 9 \\
(33 \%)\end{array}$ & $\begin{array}{l}6 / 9(67 \%) \\
(23 \text { hours } \\
\text { postexercise) }\end{array}$ & $\begin{array}{l}6 / 9(67 \%) \\
\text { (23 hours } \\
\text { postexercise) }\end{array}$ & $\mathrm{BG}<3.5 \mathrm{mmol} / \mathrm{L}$ \\
\hline Dubé et $a l^{35}$ & $4 / 11(36 \%)$ & $7 / 11(64 \%)$ & Noct $0.3(0.5)$ & Noct $0.3(0.5)$ & $\mathrm{BG}<4 \mathrm{mmol} / \mathrm{L}$ \\
\hline Guelfi et $a l^{16}$ & $1 / 7(14 \%)$ & $2 / 7(29 \%)$ & NR & NR & $\mathrm{BG}<4 \mathrm{mmol} / \mathrm{L}$ \\
\hline Iscoe and Riddell ${ }^{27}$ & $3 / 11(27 \%)$ & $7 / 11(64 \%)$ & $\begin{array}{l}\text { Evening 3/11 (27\%) } \\
\text { NR }\end{array}$ & $\begin{array}{l}\text { Evening } 5 / 11(45 \%) \\
\text { Noct } 2 / 11(18 \%)\end{array}$ & $\mathrm{BG}<4 \mathrm{mmol} / \mathrm{L}$ \\
\hline Maran et $\left.a\right|^{25}$ & $7 / 8(87 \%)$ & $\begin{array}{l}2 / 8(25 \%) \\
(p<0.05)\end{array}$ & NR & NR & $\begin{array}{l}\text { Interstitial glucose } \\
<60 \mathrm{mg} / \mathrm{dL}\end{array}$ \\
\hline Moser et $\left.a\right|^{28}$ & None & None & None & None & $\mathrm{BG}<3.3 \mathrm{mmol} / \mathrm{L}$ \\
\hline
\end{tabular}

\begin{tabular}{|c|c|c|c|c|c|}
\hline Study & $\begin{array}{l}\text { Hypos (n) during/ } \\
\text { after continuous } \\
\text { exercise }\end{array}$ & $\begin{array}{l}\text { Hypos }(n) \text { during/ } \\
\text { after resting } \\
\text { control }\end{array}$ & $\begin{array}{l}\text { Evening or } \\
\text { nocturnal hypos } \\
\text { (n) (or mean (SD)) } \\
\text { after continuous } \\
\text { exercise }\end{array}$ & $\begin{array}{l}\text { Evening or } \\
\text { nocturnal hypos } \\
\text { (n) (or mean (SD)) } \\
\text { resting control }\end{array}$ & \\
\hline Hinojosa and Heiss ${ }^{30}$ & None & None & NR & NR & Not defined \\
\hline Jankovec et al ${ }^{24}$ & None & None & NR & NR & Not defined \\
\hline Peter et $a l^{31}$ & $\begin{array}{l}1 / 13,(8 \%) 1-2 \\
\text { hours after exercise }\end{array}$ & $\begin{array}{l}2 / 13,(15 \%) 1-2 \\
\text { hours after exercise }\end{array}$ & NR & NR & $\mathrm{BG}<2.5 \mathrm{mmol} / \mathrm{L}$ \\
\hline $\begin{array}{l}\text { Rabasa-Lhoret et } \\
a^{26}\end{array}$ & 4 episodes $\ddagger$ & NR & $\begin{array}{l}22 \text { episodes in } \\
\text { total } \neq\end{array}$ & 2 episodes in total $\ddagger$ & $\begin{array}{l}\mathrm{BG}<4 \mathrm{mmol} / \mathrm{L} \text { with } \\
\text { symptoms or } \mathrm{BG} \\
<3.5 \mathrm{mmol} / \mathrm{L}\end{array}$ \\
\hline Soo et $a l^{32}$ & None & None & NR & NR & $\mathrm{BG}<3.6 \mathrm{mmol} / \mathrm{L}$ \\
\hline Yamanouchi et $\left.a\right|^{33}$ & NR & NR & NR & NR & Not defined \\
\hline \multicolumn{6}{|c|}{ Resistance exercise vs control } \\
\hline Turner et $a l^{37}$ & NR & NR & NR & NR & Not defined \\
\hline Yardley et al ${ }^{29}$ & NR & NR & $\begin{array}{l}\text { 1. } 6 / 12(50 \%) \\
\text { 2. } 2 / 10(20 \%)\end{array}$ & $4 / 11(36 \%)$ & $\mathrm{BG}<3.5 \mathrm{mmol} / \mathrm{L}$ \\
\hline
\end{tabular}

*Third exercise condition excluded as not comparable.

†64\% observed hypos above $3 \mathrm{mmol} / \mathrm{L}$.

‡Episodes of hypoglycemia not described per person.

BG, blood glucose; hypos, hypoglycemic episodes; noct, nocturnal; NR, not recorded.

five studies, and there were mixed results in the remaining studies. It is unclear if the type of exercise influences the rate of hypoglycemia or not, and the meta-analysis of IHE compared with continuous exercise showed no significant difference. For BG levels there was little difference between groups at any time point for IHE compared with continuous exercise. In continuous exercise compared with rest studies, unsurprisingly, exercise resulted in lower BG levels during and after exercise.

\section{Strengths and weaknesses}

The strength of this systematic review is the meticulous approach toward finding all relevant literature and critical appraisal of their quality to obtain the best evidence for an exercise-related strategy for adults with type 1 diabetes mellitus. Previous reviews focusing on type 1 diabetes mellitus populations irrespective of age might have introduced some bias regarding applicability of results to adult population only, since the metabolic and hormonal 


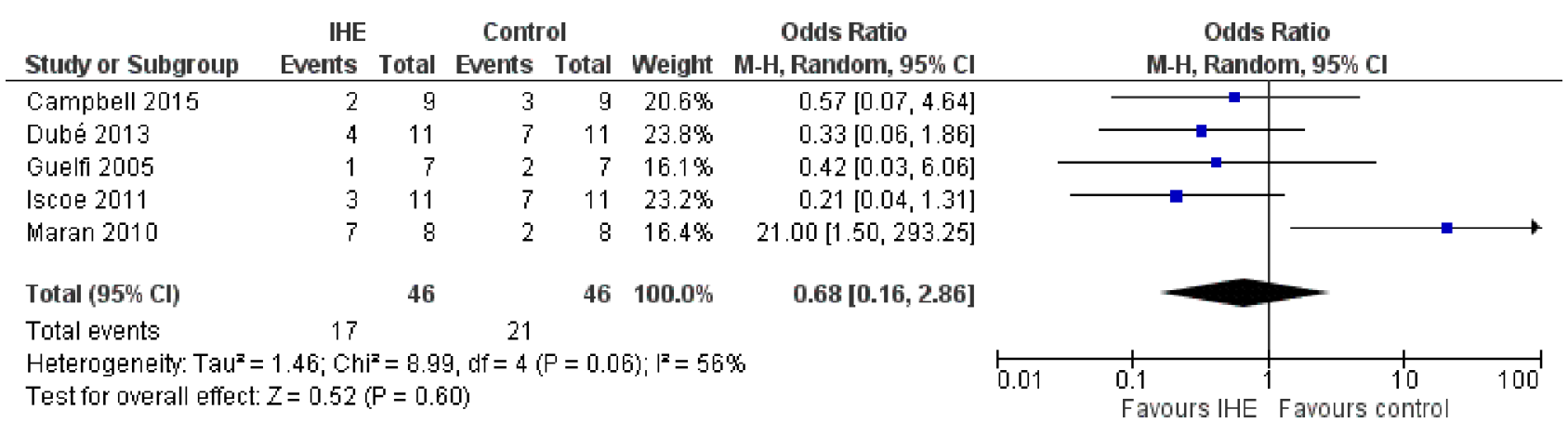

Figure 1 Meta-analysis of hypoglycemic episodes in intermittent high-intensity exercise (IHE) versus continuous exercise control. M-H, Mantel-Haentzel.

response to exercise in adult populations differs from children and adolescents. ${ }^{38}$ Moreover, this systematic review aimed to obtain the most current literature and incorporated new studies absent from previous reviews, thereby strengthening the evidence base of this systematic review. However, studies with small sample sizes can have much more widely varying results than larger studies. When small study size is coupled with publication bias where studies with null results tend not to be published, it means that systematic reviews of small studies can lead to overestimation of results, and hence the power of the systematic review may be compromised.

There are a number of factors from the included studies that limit the outcome of this systematic review. Methodological heterogeneity was observed throughout the included studies, with varying exercise protocols for IHE, continuous exercise and resistance exercises. There was a lack of standardization or reporting of pre-exercise testing diet. Methods of glucose measurement varied between studies, which may have incorporated some bias in overall results. The most accurate method of glucose measurement is blood sampling and most studies used this technique. However two studies ${ }^{28} 36$ obtained capillary blood from earlobe, a method which is more inclined to produce erroneous results. Two studies used continuous glucose monitoring (CGM) devices to obtain BG values. ${ }^{23} 27$ As measurements are obtained from interstitial fluid, there is an obvious delay in detecting the changes in BG level (mean delay $6.7 \mathrm{~min}) .{ }^{39}$ Hence, measurements from CGM devices may be less accurate compared with venous or capillary measurements. There was also heterogeneity with regard to timing of blood sampling before, during and after exercise.

Another issue is that most experiments for the IHE were conducted in laboratory-based settings using a cycle ergometer, and only one study used an intermittent running protocol to simulate sports activities. Hence, most studies did not reflect accurately on the nature of team or fieldbased sports; hence, the generalizability of the results to individuals with type 1 diabetes mellitus involved in sports activities remains in question. Also, the study participants may have been rather fitter than average people with type 1 diabetes mellitus, so the results may not be generalizable to average people with type 1 diabetes mellitus.
Most of the included studies were randomized cross-over trials, but the method of randomization was not explicitly mentioned in any studies except Bally et al. ${ }^{23}$ Information regarding blinding of participants, study personnel and health workers was also not mentioned in most studies, which might have introduced some bias. However, blinding of participants in such experiments would be difficult due to the nature of the interventions.

\section{Implications for practice}

The findings of this systematic review suggest that IHE might attenuate the decrease in BG level during and following exercise, without causing an increased risk of LOPEH, compared with continuous aerobic exercise, but there is insufficient evidence to be certain. It is important for practitioners and patients to understand the different effects of each exercise type on BG level in type 1 diabetes mellitus, for better management of exercise-related BG excursions and to encourage individuals with type 1 diabetes mellitus to participate in physical activity.

\section{Implications for research}

The results of this review are based on primary studies with small sample size, with participants with well-controlled, complication-free, type 1 diabetes mellitus. Future research should encompass larger sample sizes and involve participants with complication-free, poorly controlled type 1 diabetes mellitus $\left(\mathrm{HbA}_{1 \mathrm{C}}>10 \%\right)$ to increase the generalizability of the results. If the aim is to improve exercise rates in people reluctant to exercise, then studies should endeavor to recruit people with these characteristics. Such studies should employ rigorous standardization protocols. Future research should also investigate whether gender differences contribute to different results for each exercise type and intensity, In addition, IHE protocols should be used that reflect team sports or field activities and involve real-life situations. BG changes and potential hypoglycemia during a full game, including half-time breaks, could also be observed. If there was more research available, differences between subgroups of trained athletes compared with recreationally active participants could be evaluated. Variations in exercise protocols for IHE and resistance exercises, especially in terms of sprint durations, frequency of repetition, intensity and volume of exercise, are evident in the 
current systematic review. Hence, research incorporating a more consistent and homogeneous exercise protocol for both IHE and resistance exercise is necessary. Definitions of hypoglycemia should be standard across research.

Contributors The project was started as a masters degree dissertation by SH. SMS assisted SH to develop the question for the dissertation and supervised SH to write the dissertation. CAM worked with $\mathrm{SH}$ to convert the dissertation to a journal article, including duplicate searches and inclusion decisions. CAM checked the data extraction and conducted the meta-analysis. LHG and CJK assisted with drafting the manuscript and provided internal peer review. CAM and SH responded to external peer review comments. LHG, SMS and CJK edited the final manuscript and approved the submission.

Funding The authors have not declared a specific grant for this research from any funding agency in the public, commercial or not-for-profit sectors.

Competing interests None declared.

Patient consent Not required.

Provenance and peer review Not commissioned; externally peer reviewed.

Data sharing statement Not applicable as this is a systematic review.

Open access This is an open access article distributed in accordance with the Creative Commons Attribution Non Commercial (CC BY-NC 4.0) license, which permits others to distribute, remix, adapt, build upon this work non-commercially, and license their derivative works on different terms, provided the original work is properly cited, appropriate credit is given, any changes made indicated, and the use is non-commercial. See: http://creativecommons.org/licenses/by-nc/4.0/

\section{REFERENCES}

1. World Health Organisation (WHO), 2016. Global report on diabetes. http://apps.who.int/iris/bitstream/10665/204871/1/9789241565257_ eng.pdf?ua $=1$ (accessed 15 Dec 2017).

2. Whiting DR, Guariguata L, Weil C, et al. IDF diabetes atlas: global estimates of the prevalence of diabetes for 2011 and 2030. Diabetes Res Clin Pract 2011;94:311-21.

3. International Diabetes Federation (IDF), 2015. IDF diabetes atlas: 7th Ed. ://www.diabetesatlas.org/ (accessed 13 Dec 2017).

4. Egro FM. Why is type 1 diabetes increasing? $J$ Mol Endocrinol 2013;51:R1-13.

5. Michaliszyn SF, Shaibi GQ, Quinn L, et al. Physical fitness, dietary intake, and metabolic control in adolescents with type 1 diabetes. Pediatr Diabetes 2009;10:389-94.

6. Riddell MC, Perkins BA. Type 1 diabetes and vigorous exercise: applications of exercise physiology to patient management. Can J Diabetes 2006;30:63-71.

7. Wadén J, Forsblom C, Thorn LM, et al. Physical activity and diabetes complications in patients with type 1 diabetes: the Finnish Diabetic Nephropathy (FinnDiane) Study. Diabetes Care 2008;31:230-2.

8. National Institute for Health and Care Excellence (NICE), 2016. Type 1 diabetes in adults: diagnosis and management. https://www. nice.org.uk/guidance/ng17/chapter/1-Recommendations\#physicalactivity (accessed 16 Dec 2017)

9. Gallen I. The management of insulin treated diabetes and sport. Practical Diabetes International 2005;22:307-12.

10. Justine M, Azizan A, Hassan V, et al. Barriers to participation in physical activity and exercise among middle-aged and elderly individuals. Singapore Med J 2013;54:581-6.

11. Brazeau AS, Rabasa-Lhoret R, Strychar I, et al. Barriers to physical activity among patients with type 1 diabetes. Diabetes Care 2008;31:2108-9.

12. Riddell $\mathrm{MC}, \mathrm{Bar}-\mathrm{Or} \mathrm{O}$, Hollidge-Horvat $\mathrm{M}$, et al. Glucose ingestion and substrate utilization during exercise in boys with IDDM. J App/ Physiol 2000;88:1239-46.

13. Francescato MP, Geat M, Fusi S, et al. Carbohydrate requirement and insulin concentration during moderate exercise in type 1 diabetic patients. Metabolism 2004;53:1126-30.

14. Frier BM, Heller SR, McCrimmon RJ. Hypoglycaemia in clinical diabetes. 3rd edn. West Sussex: John Wiley \& Sons, 2014.

15. Bussau VA, Ferreira LD, Jones TW, et al. The 10-s maximal sprint: a novel approach to counter an exercise-mediated fall in glycemia in individuals with type 1 diabetes. Diabetes Care 2006;29:601-6.

16. Guelfi KJ, Jones TW, Fournier PA. Intermittent high-intensity exercise does not increase the risk of early postexercise hypoglycemia in individuals with type 1 diabetes. Diabetes Care 2005;28:416-8.
17. Yardley JE, Sigal RJ. Exercise strategies for hypoglycemia prevention in individuals with type 1 diabetes. Diabetes Spectr 2015;28:32-8.

18. Mottalib A, Kasetty M, Mar JY, et al. Weight management in patients with type 1 diabetes and obesity. Curr Diab Rep 2017;17:92.

19. American College of Sports Medicine (ACSM). ACSM's guidelines for exercise testing and prescription. 6th edn. Philadelphia: Lippincott, Williams \& Wilkins, 2000.

20. National Health Service, 2010. The hospital management of hypoglycaemia in adults with diabetes mellitus. http://www. diabetologists-abcd.org.uk/JBDS/JBDS_IP_Hypo_Adults.pdf (accessed 17 Dec 2017)

21. Critical Appraisal Skills Programme (CASP), 2017. CASP randomised controlled trial checklist. http://docs.wixstatic.com/ ugd/dded87_4239299b39f647ca9961f30510f52920.pdf (accessed 18 Dec 2017).

22. Higgins JP, Green S, 2011. Cochrane handbook for systematic reviews of interventions, version 5.1.0. The cochrane collaboration. www.handbook.cochrane.org (accessed 14 Apr 2017).

23. Bally L, Zueger T, Buehler T, et al. Metabolic and hormonal response to intermittent high-intensity and continuous moderate intensity exercise in individuals with type 1 diabetes: a randomised crossover study. Diabetologia 2016;59:776-84.

24. Jankovec Z, Krcma M, Gruberova J, et al. Influence of physical activity on metabolic state within a 3-h interruption of continuous subcutaneous insulin infusion in patients with type 1 diabetes. Diabetes Technol Ther 2011;13:1234-9.

25. Maran A, Pavan P, Bonsembiante B, et al. Continuous glucose monitoring reveals delayed nocturnal hypoglycemia after intermittent high-intensity exercise in nontrained patients with type 1 diabetes. Diabetes Technol Ther 2010;12:763-8.

26. Rabasa-Lhoret R, Bourque J, Ducros F, et al. Guidelines for premeal insulin dose reduction for postprandial exercise of different intensities and durations in type 1 diabetic subjects treated intensively with a basal-bolus insulin regimen (ultralente-lispro). Diabetes Care 2001;24:625-30.

27. Iscoe KE, Riddell MC. Continuous moderate-intensity exercise with or without intermittent high-intensity work: effects on acute and late glycaemia in athletes with Type 1 diabetes mellitus. Diabet Med 2011;28:824-32.

28. Moser O, Tschakert G, Mueller A, et al. Effects of high-intensity interval exercise versus moderate continuous exercise on glucose homeostasis and hormone response in patients with type 1 diabetes mellitus using novel ultra-long-acting insulin. PLoS One 2015;10:e0136489.

29. Yardley JE, Kenny GP, Perkins BA, et al. Resistance versus aerobic exercise: acute effects on glycemia in type 1 diabetes. Diabetes Care 2013;36:537-42.

30. Hinojosa SL, Heiss CJ. A study examining the effect of a short bout of postprandial walking on the glycemic effect of a meal: type 1 diabetes. J Am Coll Nutr 2017;36:654-9.

31. Peter R, Luzio SD, Dunseath G, et al. Effects of exercise on the absorption of insulin glargine in patients with type 1 diabetes. Diabetes Care 2005;28:560-5.

32. Soo K, Furler SM, Samaras K, et al. Glycemic responses to exercise in IDDM after simple and complex carbohydrate supplementation. Diabetes Care 1996;19:575-9.

33. Yamanouchi K, Abe R, Takeda A, et al. The effect of walking before and after breakfast on blood glucose levels in patients with type 1 diabetes treated with intensive insulin therapy. Diabetes Res Clin Pract 2002;58:11-18.

34. Campbell MD, West DJ, Bain SC, et al. Simulated games activity vs continuous running exercise: a novel comparison of the glycemic and metabolic responses in T1DM patients. Scand $J$ Med Sci Sports 2015;25:216-22.

35. Dubé MC, Lavoie C, Weisnagel SJ. Glucose or intermittent highintensity exercise in glargine/glulisine users with T1DM. Med Sci Sports Exerc 2013;45:3-7.

36. Guelfi KJ, Jones TW, Fournier PA. The decline in blood glucose levels is less with intermittent high-intensity compared with moderate exercise in individuals with type 1 diabetes. Diabetes Care 2005;28:1289-94

37. Turner D, Luzio S, Gray BJ, et al. Impact of single and multiple sets of resistance exercise in type 1 diabetes. Scand $\mathrm{J} \mathrm{Med} \mathrm{Sci}$ Sports 2015;25:e99-e109.

38. Riddell MC. The endocrine response and substrate utilization during exercise in children and adolescents. J Appl Physiol 2008;105:725-33.

39. Bilous R, Donnelly R. Handbook of Diabetes. 4th edn. West Sussex: Blackwell Publishing, 2010. 